\title{
Income Attainment among Victims of Violence: Results From a Preliminary Study
}

\author{
M. J. J. Kunst $\cdot$ S. Bogaerts $\cdot$ T. Wilthagen $\cdot$ F. W. Winkel
}

Accepted: 7 February 2009/Published online: 24 February 2009

(C) The Author(s) 2009. This article is published with open access at Springerlink.com

\begin{abstract}
Violent victimisation may have many short-term psychological and physical outcomes. Occasionally, the negative aftermath of violence persists over time or induces other and more far-reaching consequences. Income attainment after victimisation is one of these outcomes. To date, previous studies have focussed on the income effects of violent victimisation during childhood and adolescence. Violence exposure during the early stages of the life course may frustrate processes of educational and occupational attainment and consequentially result in lower income levels. However, in addition or alternatively, many other and age-independent pathways between violent victimisation and income may be suggested. Prior studies appear to have paid little attention to this issue. Therefore, the purpose of the current study was to explore whether violent victimisation is associated with income levels several years after victimisation, irrespective of the age at which victimisation occurs. Victims of violence were recruited through the Dutch Victim Compensation Fund. To preliminary estimate the effect of violent victimisation on income, a comparable control group of non-victims was composed. The study sample contained 206 victims and 173 non-victims. Both bivariate correlational and multivariate statistical techniques suggested that violent victimisation is a significant predictor of income. Implications of the presented results were discussed with regard to future research and policy practice.
\end{abstract}

Keywords Violent victimisation · Income attainment

M. J. J. Kunst ( $₫)$

Faculty of Law, The International Victimology Institute Tilburg, Tilburg University, Building M, Room 901, P.O. Box 90153, 5000 LE Tilburg, The Netherlands e-mail: m.j.kunst@uvt.nl

S. Bogaerts - T. Wilthagen $\cdot$ F. W. Winkel

Faculty of Law, The International Victimology Institute Tilburg, Tilburg University, P.O. Box 90153, 5000 LE Tilburg, The Netherlands 


\section{Introduction}

An extensive body of research suggests that violent victimisation can have a wide array of negative short-term psychological consequences for the victim involved, such as anger (e.g. Andrews et al. 2000; Feeney et al. 2000), revenge (Orth 2003), anxiety (e.g. Herek et al.1999), depression (e.g. Sorenson and Golding 1990) and posttraumatic stress disorder (PTSD) symptoms (e.g. Orth et al. 2008; Wohlfarth et al. 2003). In addition, many victims may experience diverging minor or major physical injuries (e.g. Amar and Gennaro 2005; Brink et al. 1998) or psychosomatic complaints (e.g. Nerøien and Schei 2008; Berkowitz 1998) as a result of the act of violence. Fortunately though, most victims return to their previctimisation levels of functioning within several months of the act of violence (e.g. Norris and Kaniasty 1994). However, occasionally, the negative aftermath of violence persists or induces other and more far-reaching consequences. In this paper we will focus on one such outcome in particular: income attainment.

From a theoretical perspective, the relationship between negative life events and income may be suggested to develop through a sequential causal chain of events which may differ according to the nature and severity of the event, the individual characteristics of the victim involved and, most importantly, its timing during the life course; life events that occur during pivotal stages of personal and social development play an important role in shaping life course trajectories (Elder 1994).

Macmillan (1998, 2000, 2001) used these premises as a starting-point to formulate a theory of adolescent victimisation and income attainment during adulthood (see also Macmillan and Hagan 2004). Briefly summarised, he argued that most violent victimisation experiences take place in adolescence, while the mental and physical health consequences of victimisation during adolescence of the life course may influence later income attainment through disruption of educational and occupational attainment processes. In his view, for the victim involved the act of violence reflects a certain vulnerability to harm that is outside his or her individual control. Experiencing this vulnerability may result in changes of perceived agency and self-efficacy. Subsequently, altered perceptions of the self as an active agent may account for the wide array of consequences that follow victimisation. With regard to earnings in adulthood, he suggested that diminished self-images in adolescence may lead to lower school investments and thereupon in lower grades and less overall educational attainment. Ultimately, attained education level determines occupational and income status later in life (Macmillan 2000, pp. 557-559).

Macmillan (2000) provided preliminary empirical evidence for his line of reasoning by establishing relationships between adolescent victimisation and income in adulthood. More specifically, using data from the 1976-1987 US National Youth Survey and the 1993 Canadian General Social Survey, he demonstrated that those victimised in adolescence (i.e. before the age of 18) had lower average hourly wages and annual personal income than non-victims. In addition, he showed that individuals victimised at age 18-19 earned less than non-victims of the same age, while the same did not apply to older age categories. In all analyses the effect sizes for violent victimisation were substantially reduced after adjustment for educational and occupational attainment.

However, in addition to the developmental pathway proposed by Macmillan, or alternatively, one might argue that violent victimisation can also affect human capital and income during later stages of the life course. For example, through postponed or cancelled job transitions, long periods of sickness absence, spells of unemployment and even permanent disability leave or premature retirement, working victims may suffer income loss, while those not active on the labour market yet in search of work may struggle to find a job 
matching their potential. Partial support for this hypothesis is provided by economic studies on the impact of functional impairment (e.g. Randolph 2004) and periods of non-participation in work (Arulampalam 2001). These effects may occur irrespective of the age at which one is victimised and may even sustain after retirement. Finally, victimisation among elderly may force them to break into their reserves due to increased medical costs (e.g. Miller et al. 1993). As a result, they will lose interest income from savings or investments.

Surprisingly, the suggested age-independent relation between violent victimisation and income does not seem to have received much attention in the relevant criminological and victimological literature. Therefore, the first purpose of this study was to explore whether such a link exists. As an initial examination, the study was not developed to unravel the exact nature of the possible pathways between violent victimisation and successive income attainment. However, there is little reason for future researchers to study these linkages if preliminary studies have failed to show a direct relationship between violent victimisation and income attainment in the first place. The second purpose of the study was to replicate the effect for adolescent victimisation shown by Macmillan (2000).

\section{Methods}

\subsection{Procedure and Participants}

The study was conducted in May and June 2008. Victims of various types of violence were recruited through the Dutch Victim Compensation Fund. Victims of violent offences can apply to the fund for a single payment if they have suffered physical or psychological damage and cannot be compensated through other means. 768 potential participants who had applied for compensation in 2005 and had consented to be approached for research were approached with a letter that explained the purpose of the study and invited them to fill out a survey through the internet or to request for a hardcopy version if they did not have access to the World Wide Web or preferred to fill out the questionnaire on paper. About 264 victims started filling out the questionnaire through the internet, while 50 completed the paper-and-pencil version, yielding a response rate of $41 \%$.

A comparison group of non-victims was mainly composed by dispersion of $\sim 20.000$ unaddressed leaflets in 15 postal code areas randomly selected in each province of the Netherlands. Leaflets contained information comparable to that provided to the victimgroup and the URL of the website hosting the questionnaire for the comparison group. This strategy resulted in a comparison group of 283 respondents who had either completely or partly filled out the survey. One of them filled out the questionnaire on paper. Budgetary constraints limited us in recruiting participants for the control group through more randomised procedures, such as random digit dialing.

Only respondents without missing values were included in statistical analyses. Missing data on study variables were not estimated using statistical imputation procedures, since the program running the internet questionnaires did not allow participants to skip a particular question and to continue with the next question. Consequently, the pattern of missingness for successive questions could not be investigated. An additional exclusion criterion for victims was age under 16 years at time of victimisation in order to be able to statistically adjust for childhood adversities other than victimisation. Additional exclusion criteria for controls were age under 16 years at time of study entry and self-reported history of violence. Participants under the age of 16 could not have earned a living with a legitimate job, since paragraph 1 of article 7:612 of the Dutch Civil Code does not allow the conclusion of a 
labour contract until one has reached the age of 16. Inclusion of participants in the comparison group with victimisation experiences was not deemed appropriate due to a lack of information concerning the timing and nature of the acts involved.

About 233 victims (74.2\%) and 185 controls (65.4\%) did not have missing values on any of the study variables. 27 participants in the victim-group were excluded from statistical analyses, since they had not reached the age of 16 at time of victimisation. Twelve participants in the comparison group were excluded from statistical analyses, since they had reported a history of violence exposure. Thus, the final study sample consisted of 206 victims and 173 controls (Fig. 1). The number of years passed since victimisation ranged between 2.7 and 31.7 years $(M=5.0, \mathrm{SD}=5.2)$. Approval for the study was obtained from the internal board of directory of the fund.

\subsection{Measures}

Outcome variable. Income was the study's sole outcome variable and was measured by a single item that enabled participants to indicate their "approximate gross annual income" on a 5-category item ( $€ € 10.000$; €10.000-€20.000; €20.000-€30.000; €30.000-€40.000; $>€ 40.000$ ). Respondents were asked to estimate the total of their personal earnings from paid employment, benefits, pension and other sources. Assessing income in this manner was preferred above using open-ended questions, for it is a common method in studies on income determinants (e.g. Randolph 2004; Judge and Cable 2004) and allows participants to provide a rather rough indication of their income and is therefore more likely to prevent missing data (e.g. Hinze 2000), especially when using a web-based survey (e.g. Joinson et al. 2008). Since each category represented an equally large income interval, selfreported income was treated as a continuous variable in regression analyses. The distribution of income slightly departed from normality due to positive skewness. Transformation of scores did not improve the distribution of income. However, since the study sample contained more than 100 respondents, the impact of non-normality could be deemed negligible (Tabachnick and Fidell 2007).

Primary predictor variable. Violent victimisation was the main predictor variable of interest. Application for compensation with the fund was used as an indicator of violent victimisation. A single question was administered among controls to determine whether they had ever been exposed to an act of violence (Kunst et al. 2008). In order to test
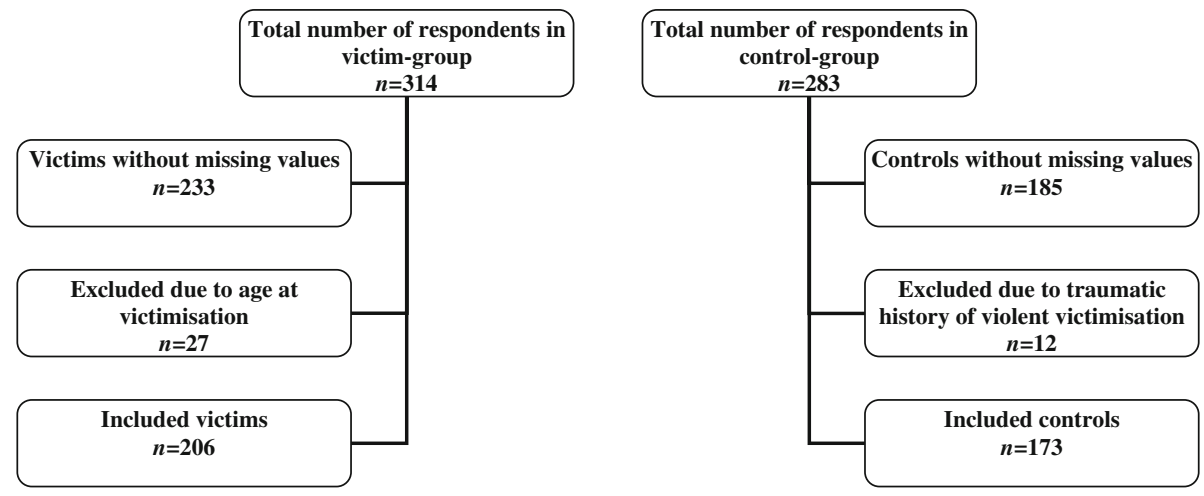

Fig. 1 Flowchart of study participants in victim- and control-group 
whether the timing of victimisation was predictive, a variable was computed that reflected victimisation below the age of 20. The cut-off used followed on Macmillan's results discussed in the introduction (Macmillan 2000).

Secondary predictor variables. In order to be able to statistically adjust for the potential influence of known determinants of income, several factors were assessed.

First, a set of relevant demographic variables was measured, including age, gender, level of education and occupational status. Many previous studies have shown associations between these factors and income level (e.g. Sharpe and Abdel-Ghany 2006; Larson and Morris 2008; Scullin et al. 2000; King 2000). For participants recruited through the fund, information on age and gender was extracted from their electronic files. Among controls, age and gender were measured by asking respondents to report their date of birth and gender. Level of education was assessed using a single item that differentiated between six ranked levels of education $(1=$ elementary school, $2=$ secondary school, $3=$ lower vocational education, $4=$ intermediate vocational education, $5=$ higher vocational education/bachelor degree, $6=$ university/master degree). To register participants' occupational status, two specific questions were developed that took into account the diverging ways in which people can legitimately generate income in the Netherlands, both during years of potential participation in the labour force and afterwards. First, participants were asked whether they were involved in paid work (salaried employed or self-employed) at the time of survey completion and, if so, whether they were full-time or part-time employed. Second, they were instructed to indicate whether they received income from non-work sources (disability compensation benefit, unemployment benefit, welfare receipts, early retirement pension, retirement pension, old age state pension), either complementary to work earnings or as a prime source of income. Based on their answers, respondents were categorized as full-time working $=2$, part-time $=1$ and not-working $=0$.

Second, current health status was surveyed. Especially within the field of economics, poor health has been suggested to have a negative impact on economic resources (e.g. Smith 1999). Health status was estimated by online administration of a list of 19 chronic disease conditions experienced in the past 12 months. The content of the list and the time-frame used were derived from the Dutch Local and National Health Monitor (National Institute of Public Health and the Environment [RIVM], 2005) and followed upon previous research (Wilber et al. 2002). The following conditions could be scored: diabetis mellitus; cerebrovascular disease; myocard infarct; other cardiovascular disease; cancer; depression; migraine headache; high blood pressure; peripheral vascular disease; asthma, chronic bronchitis, emphysema or COPD; serious or persistent gastrointestinal disorder ( $>3 \mathrm{mo}$ ); psoriasis; chronic eczema; involuntary urine loss (incontinence); serious or persistent lower back pain (including hernia); hip and knee arthritis; rheumatoid arthritis; other serious or persistent neck or shoulder disease and other serious or persistent elbow, wrist or hand disease. An open category was used to give participants the opportunity to report conditions not included in the list. Participants were only considered to be suffering from a chronic condition if they had been diagnosed by a professional physician. Online surveys have also been used in other studies to identify individuals with chronic conditions (Leveille et al. 2008).

Third, respondents were asked to report their body height. A number of studies from different scientific fields (e.g. Rashad 2008) stress the importance of using body height as a control variable in income research, since it can be used both as a proxy variable for many factors thought to affect income levels, such as nutrition and physical health during childhood (e.g. Deaton 2007), self-esteem and evaluation by others in terms of social status (e.g. Judge and Cable 2004) and physical attractiveness (e.g. French 2002; Macintyre and West 1991). In this study, body height was mainly included as an indicator of childhood adversity. 
Due to differences in timing of growth spurt in puberty and the amount of height loss after the age of 45 (Rashad 2008), body height may partly have reflected age at time of study entry. However, this issue can be overcome by estimating the effects of age and height on income in statistical analyses simultaneously (e.g. Judge and Cable 2004). Body height was assessed by asking participants to report their height in centimeters. Recently, Luce et al. (2007) have shown online height reportings do not differ from paper-and-pencil responses.

\subsection{Data Analysis}

Means and standard deviations were calculated for each of the variables under investigation. Student's $t$-tests were carried out to reveal differences between victims and nonvictims on income, age, gender, height, education level, occupational status and current health status. Zero order correlations were computed to determine univariate relations within groups. A multivariate linear regression analysis was performed to estimate the independent effect of violent victimisation on current income after adjusting for potential confounders. All statistical analyses were performed using the software package SPSS 16.0 for Windows (SPSS Inc, Chicago, Illinois).

\section{Results}

\subsection{Preliminary Analyses}

Table 1 presents descriptive statistics for victims and non-victims and intercorrelations among study variables within each group. Adolescent victimisation is not included in the table, since only participants in the victim-group could be assigned to this category. Victims and non-victims differed in income, yet no differences were observed on any of the available control variables. Age, gender, height and occupational status correlated positively with income in both groups. Negative associations were found for the relationships between current health status and income. The relation between education level and income was only significant in the victim-group. Adolescent victimisation correlated significantly with income $(r=-.20, p<.01)$.

\subsection{Relationship between violent victimisation, income and control variables}

As can be seen in Table 2, violent victimisation was an independent predictor of income after adjusting for age, gender, height, education level, occupational status and current health status. In contrast to univariate correlational analysis, no meaningful effect was observed for adolescent victimisation. Except for current health status, all control variables included in the model were independent predictors of income. ${ }^{1}$

\section{Discussion}

The present study was developed to explore the relationship between violent victimisation and income. Both univariate and multivariate analyses indicated that violent victimisation is negatively associated with income level. However, in contrast with previous research

\footnotetext{
1 Additional analyses revealed that the effect for age did not apply to participants older than 65 .
} 


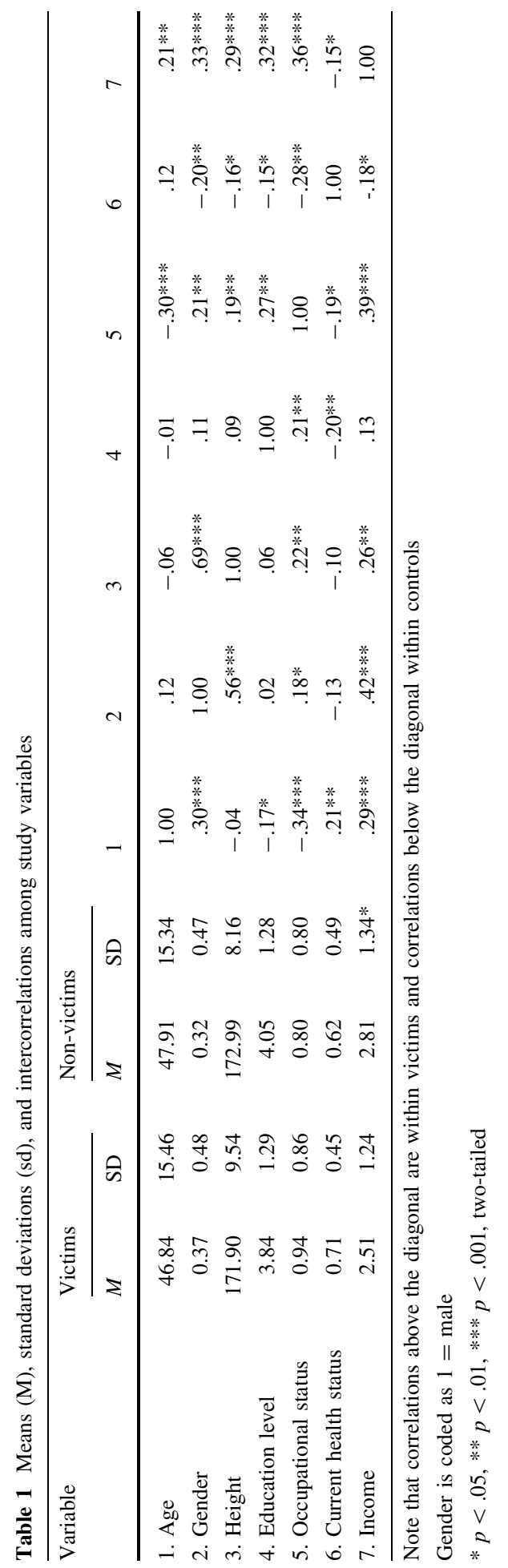


Table 2 Results of regression of income on violent victimisation and control variables

\begin{tabular}{lclll}
\hline Variables & \multicolumn{1}{l}{ B } & SE (B) & $\beta$ & $R^{2}$ \\
\hline Age & .032 & .004 & $.385^{* * *}$ & $.371^{* * * *}$ \\
Gender & .331 & .157 & $.122^{*}$ & \\
Height & .017 & .008 & $.115^{*}$ & \\
Violent victimisation & -.308 & .114 & $-.119^{* *}$ & \\
Adolescent victimisation & .091 & .240 & .017 & \\
Education & .137 & .043 & $.136^{* *}$ & \\
Occupational status & .614 & .073 & $.396^{* * *}$ & \\
Current health status & -.207 & .120 & -.075 & \\
\hline
\end{tabular}

$* p<.05, * * p<.01, * * p<.001$

(e.g. Macmillan 2000), a deterrent effect for victimisation during adolescence was only found in bivariate correlation analysis.

Due to its exploratory nature, the results should be considered preliminary rather than conclusive. Additional research is required to further unravel income trajectories among victims of violence and their determinants. Future studies should preferably use a longitudinal design in order to be able to establish causal connections between study variables and make use of a sample large enough to make adequate statistical comparisons between victims and non-victims. Due to the low rate of (severe) cases of violence in the general population, they are likely to turn out to be expensive and time-consuming operations. In addition, access to employment records and qualitative data are necessary to describe the exact course of events between victimisation and income. Due to the complex design of social security systems in Western European countries, many labour market pathways for victims may be distinguished. For example, in the Netherlands, occupationally active victims with a work contract of undetermined duration cannot suffer income loss due to health problems experienced as a result of their victimisation experience until 12 months have passed since the first day of reported sickness. Up to that moment, the employer is legally obliged to cover $100 \%$ of the victim's loss of earning power. After this period, $70 \%$ should be covered during the following 12 months, while the remaining $30 \%$ may be covered by collective compensation agreements between employers and private insurance companies. In addition, an employer may be sanctioned to pay the victim's wages during another period of maximum 12 months, if the employer has put too little effort in work reintegration. Because substantial time may have passed since the act of victimisation until one decides to report sick, actual loss of income may not occurr until several years after victimisation. In contrast, other victims active in the labour market may already experience income loss rather soon due to terminations of temporary contracts, whereas victims without a paid job may be financially punished for failing to meet requirements of employees' insurance or welfare schemes. Information of this nature is not very likely to be obtained reliably through questionnaires.

Although the results of the current study may be primarily interpreted as a prerequisite necessary to justify a more thorough investigation of victims' career trajectories over the life course, they may be considered relevant in itself as well. Based on the concept of victim proneness developed by Von Hentig (1948), it may be argued that violent victimisation merely reflects a general vulnerability to be rebuffed by others in one's interpersonal relations due to individual biological, psychological or social characteristics that can lead to disadvantages in many areas of functioning. With regard to the labour market, this vulnerability may manifest itself in the failure to be granted a promotion or 
find a job and eventually result in lower earnings (e.g. Van Ham 2001). If so, history of violent victimisation may be used as an indicator of future career success, for example during job application courses and attempts by public or private agencies to reintegrate people into work after spells of non- participation. Future research is necessary to determine which underlying factors actually prevent wage gain from occurring. Some of them, such as behavioural ones, may be easily modified, while others, such as congenital physical attributes, may not. Fortunately, the present findings give reason to tentatively conclude that being a victim encompasses more than lacking height.

Finally, several study limitations must be mentioned. First, we were not able to address the issue of endogeneity. Endogeneity arises when an independent variable is correlated with the error term in a regression model (Wooldridge 2002). Broadly stated, endogeneity can occur when 1) variables correlated with the dependent variable are omitted from the regression, 2) causality between the regressor(s) and the dependent variable runs in both directions (recursivity) or when 3) independent variables are measured with error (e.g. Bascle 2008). The Hausman test is commonly used to test for endogeneity (Hausman 1978). If endogeneity exists, methods of instrumental variables (IV) can be used to solve the problem of endogeneity. An often applied procedure in economic literature for dealing with the first and third types of endogeneity is the two-stage least-squares approach (2SLS). In 2SLS, the endogenous variables are first regressed on the instruments (i.e. variables assumed to be correlated with the endogenous explanatory variables and to have no association with the outcome variable) and covariates to obtain their predicted values. Subsequently, the predicted values are included in the regression model in place of the original exogenous variables (e.g. Stock 2001). In the case of recursivity, simultaneous estimation techniques, such three-stage-least-squares (3SLS) and maximum likelihood estimation (MLE), are required, since they are more efficient (Larcker and Rusticus 2008). However, unfortunately, our data did not contain variables suitable for proper performance of any of these instrumental variable methods. As a result, the obtained effect for violent victimisation on income may be over- or underestimated. The possible bias can be assumed to be rather low though, since our regression equation contained more than one endogenous variable and previous studies have suggested that biases introduced through failure to control for endogeneity tend to cancel one another out (e.g. Card 2001).

Second, we were not able to determine whether the victims included in our study were representative of victims of violence in the general population. A minimum prerequisite for doing so is the availability of a data set on background characteristics of victims in the Netherlands and the nature and severity of the violence inflicted upon them. However, unfortunately, existing crime surveys do not contain sufficiently specific information on the latter. The potential lack of representativeness does not necessarily invalidate the results of our study though, since we included a control group that was similar to the victim group in many respects to estimate the effect of violence on income. Furthermore, even after keeping the effects of age, gender, height, education level, occupational status and current health status constant, violent victimisation remained a significant predictor of income attainment.

Despite these limitations, the present study seems to be the first to assess the relationship between violent victimisation and income irrespective of age. Furthermore, where previous studies relied on self-reported exposure to violent behaviours (e.g. Macmillan 2000), we used a rather objective indicator of violent victimisation.

Acknowledgments The authors thank the Dutch Victim Compensation Fund for their financial and organisational support with the data collection. They also thank the participants for their cooperation and the reviewers for their thoughtful and helpful comments on the original manuscript. 
Open Access This article is distributed under the terms of the Creative Commons Attribution Noncommercial License which permits any noncommercial use, distribution, and reproduction in any medium, provided the original author(s) and source are credited.

\section{Appendix 1}

See Fig. 1.

\section{Appendix 2}

See Tables 1 and 2 .

\section{References}

Amar, A.f., \& Gennaro, S. (2005). Dating violence in college women: Associated physical injury, healthcare usage, and mental health symptoms. Nursing Research, 54, 235-242. doi:10.1097/00006199200507000-00005.

Andrews, B., Brewin, C. R., Rose, S., \& Kirk, M. (2000). Predicting PTSD symptoms in victims of violent crime: The role of shame, anger, and childhood abuse. Journal of Abnormal Psychology, 109, 69-73. doi:10.1037/0021-843X.109.1.69.

Arulampalam, W. (2001). Is unemployment really scarring? effects of unemployment experiences on wages. The Economic Journal, 111, F585-F606. doi:10.1111/1468-0297.00664.

Bascle, G. (2008). Controlling for endogeneity with instrumental variables in strategic management research. Strategic Organization, 6, 285-327.

Berkowitz, C. D. (1998). Medical consequences of child sexual abuse. Child Abuse and Neglect, 22, $541-550$.

Brink, O., Vesterby, \& Jensen, J. (1998). Pattern of injuries due to interpersonal violence. Injury, 29, 705-709. doi:10.1016/S0020-1383(98)00176-4.

Card, D. (2001). Estimating the return to schooling: Progress on some persistent econometric problems. Econometrica, 69, 1127-1160. doi:10.1111/1468-0262.00237.

Deaton, A. (2007). Height, health, and development. Proceedings of the National Academy of Sciences of the United States of America, 104, 13232-13237. doi:10.1073/pnas.0611500104.

Elder, G. (1994). Time, human agency, and social change: Perspectives on the life course. Social Psychology Quarterly, 57, 4-15. doi:10.2307/2786971.

Feeney, N. C., Zoelnner, L. A., \& Foa, E. B. (2000). Anger, dissociation, and posttraumatic stress disorder among female assault victims. Journal of Traumatic Stress, 13, 89-100. doi:10.1023/A:100772 5015225 .

French, M. T. (2002). Physical appearance and earnings: Further evidence. Applied Economics, 34, 569-572. doi:10.1080/00036840010027568.

Hausman, J. A. (1978). Specification tests in econometrics. Econometrica, 46, 1251-1272.

Heckman, J. J. (1998). Detecting discrimination. The Journal of Economic Perspectives, 12, $101-116$.

Herek, G. M., Gillis, J. R., \& Cogan, J. C. (1999). Psychological sequelae of hate-crime victimization among lesbian, gay, and bisexual adults. Journal of Consulting and Clinical Psychology, 67, 945-951. doi: 10.1037/0022-006X.67.6.945.

Hinze, S. W. (2000). Inside medical marriages. The effect of gender on income. Work and Occupations, 27, 464-499. doi:10.1177/0730888400027004003.

Joinson, A. N., Paine, C., Buchanan, T., \& Reips, U. D. (2008). Measuring self-disclosure online blurring and non-response to sensitive items in web-based surveys. Computers in Human Behavior, 24, 21582171. doi:10.1016/j.chb.2007.10.005.

Judge, T. A., \& Cable, D. M. (2004). The effect of physical height on workplace succes and income: Preliminary test of a theoretical model. The Journal of Applied Psychology, 89, 428-441. doi: 10.1037/0021-9010.89.3.428. 
King, J. E. (2000). Part-time workers' earnings: Some comparisons. Compensation and Working Conditions, Summer, 2000, 27-36.

Kunst, M. J. J., Van der Aa, S., Winkel, F. W., \& Bogaerts, S. (2008). Recent history of criminal victimisation, trait negative affectivity and psychosocial adjustment problems following negative life events in a Dutch population sample. An exploratory study. Manuscript submitted for publication.

Larcker, D. F., \& Rusticus, T. O. (2008). On the Use of Instrumental Variables in Accounting Research. Retrieved December 12, 2008, from http://ssrn.com/abstract=694824.

Larson, P. D., \& Morris, M. (2008). Sex and salary: A survey of purchasing and supply professionals. Journal of Purchasing and Supply Management, 14, 112-124. doi:10.1016/j.pursup.2008.02.002.

Leveille, S., Huang, A., Tsai, S., Weingart, S., \& Iezzoni, L. (2008). Screening for chronic conditions using a patient internet portal: Recruitment for an internet-based primary care intervention. Journal of General Internal Medicine, 23, 472-475.

Luce, K. H., Winzelberg, A. J., Das, S., Osborne, M. I., Bryson, S. W., \& Taylor, C. B. (2007). Reliability of self-report: paper versus online administration. Computers in Human Behavior, 23, 1384-1389. doi: 10.1016/j.chb.2004.12.008.

Macintyre, S., \& West, P. (1991). Social, developmental and health correlates of "attractiveness" in adolescence. Sociology of Health \& Illness, 13, 149-167. doi:10.1111/1467-9566.ep11340769.

Macmillan, R. (1998). Growing up scared: The effects of violent victimization in adolescence on adult socioeconomic attainment. Unpublished doctoral dissertation, University of Toronto, Toronto, Ontario, Canada.

Macmillan, R. (2000). Adolescent victimization and income deficits in adulthood: Rethinking the costs of criminal violence from a life course perspective. Criminology, 38, 553-588. doi:10.1111/ j.1745-9125.2000.tb00899.x.

Macmillan, R. (2001). Violence and the life course: The consequences of victimization for personal and social development. Annual Review of Sociology, 27, 122. doi:10.1146/annurev.soc.27.1.1.

Macmillan, R., \& Hagan, J. (2004). Violence in the transition to adulthood: Adolescent victimization, education, and socioeconomic attainment in later life. Journal of Research on Adolescence, 14, 127158. doi:10.1111/j.1532-7795.2004.01402001.x.

Miller, T. R., Cohen, M. A., \& Rossman, S. B. (1993). Victim costs of violent crime and resulting injuries. Health Affairs, 12, 186-197. doi:10.1377/hlthaff.12.4.186.

Nerøien, A. I., \& Schei, B. (2008). Partner violence and health: Results from the first national study on violence against women in Norway. Scandinavian Journal of Public Health, 36, 161-168. doi: $10.1177 / 1403494807085188$.

Norris, F. H., \& Kaniasty, K. (1994). Psychological distress following criminal victimization in the general population: Cross-sectional, longitudinal, and prospective analyses. Journal of Consulting and Clinical Psychology, 62, 111-123. doi:10.1037/0022-006X.62.1.111.

Orth, U. (2003). Punishment goals of crime victims. Law and Human Behavior, 27, 173-186. doi: 10.1023/A:1022547213760.

Orth, U., Cahill, S. P., Foa, E. B., \& Maercker, A. (2008). Anger and posttraumatic stress disorder symptoms in crime victims: A longitudinal analysis. Journal of Consulting and Clinical Psychology, 76, 208-218. doi:10.1037/0022-006X.76.2.208.

Randolph, D. S. (2004). Predicting the effect of disability on employment status and income. Work: A Journal of Prevention. Assessment and Rehabilitation, 23, 257-266.

Rashad, I. (2008). Height, health, and income in the US, 1984-2005. Economics and Human Biology, 6, $108-126$.

Rijksinstituut voor Volksgezondheid en Milieu (2005). Lokale en Nationale Monitor Gezondheid: Indicatoren voor de Monitor Volksgezondheid: Chronische aandoeningen-basis. [Local and National Health Monitor: Indicators from the Public Health Monitor: Chronic Health Conditions-basic questionnaire]. Retrieved December 10, 2008, from http://www.monitorgezondheid.nl/volksindicatoren. aspx.

Scullin, M. H., Peters, E., Williams, W. M., \& Ceci, S. J. (2000). The role of IQ and education in predicting later labor market outcomes Implications for affirmative action. Psychology, Public Policy, and Law, 6, 63-89. doi:10.1037/1076-8971.6.1.63.

Sharpe, D. L., \& Abdel-Ghany, M. (2006). Determinants of income differentials: Comparing asians with whites and blacks. Journal of Economic Issues, 27, 588600.

Sorenson, S. B., \& Golding, J. M. (1990). Depressive sequelae of recent criminal victimization. Journal of Traumatic Stress, 3, 337-350.

Stock, J. H. (2001). Instrumental variables in statistics and econometrics. In N. J. Smelser \& P. B. Baltes (Eds.), International encyclopaedia of the behavioural sciences (pp. 7577-7582). New York: Elsevier. 
Tabachnick, B. G., \& Fidell, L. S. (2007). Using multivariate statistics (5th ed.). Boston, MA: Allyn and Bacon/Pearson Education.

Van Ham, M. (2001). Workplace mobility and occupational achievement. International Journal of Population Geography, 7, 295-306. doi:10.1002/ijpg.225.

Von Hentig, H. (1948). The criminal and his victim. New Haven: Yale University Press.

Wilber, N., Mitra, M., Walker, D. K., Allen, D., Meyers, A. R., \& Tupper, P. (2002). Disability as a public health issue: Findings and reflections from the Massachusetts survey of secondary conditions. The Milbank Quarterly, 80, 393-421.

Wohlfarth, T. D., Van den Brink, W., Winkel, F. W., \& Ter Smitten, M. (2003). Screening for posttraumatic stress disorder: An evaluation of two self-report scales among crime victims. Psychological Assessment, 15, 101-109. doi:10.1037/1040-3590.15.1.101.

Wooldridge, J. M. (2002). Econometric analysis of cross section and panel data. Cambridge: MIT Press. 